Article

\title{
Are Religious Teens Nice Kids? Faith and Congeniality among American Adolescents
}

\author{
Kristi M. Fondren ${ }^{1}$, John P. Bartkowski ${ }^{2, *}{ }^{\mathbb{C}}$, Xiaohe $\mathrm{Xu}^{2,3}$ and Martin L. Levin ${ }^{4}$ \\ 1 Department of Sociology and Anthropology, Marshall University, Huntington, WV 25755, USA; \\ fondren@marshall.edu \\ 2 Department of Sociology, University of Texas at San Antonio, San Antonio, TX 78249, USA; \\ xiaohe.xu@utsa.edu \\ 3 The School of Public Administration, Sichuan University, Chengdu 610064, China \\ 4 Department of Sociology, University of Memphis, Memphis, TN 38152, USA; martin.levin@memphis.edu \\ * Correspondence: john.bartkowski@utsa.edu; Tel.: +1-210-508-2530
}

Received: 19 September 2018; Accepted: 23 October 2018; Published: 26 October 2018

check for updates

\begin{abstract}
One body of extant research has documented the social contours and positive effects of teen religiosity, while another has explored the religious sources of social congeniality ("niceness") among adult Americans. This study integrates these parallel bodies of scholarship by examining the religious bases of niceness among American teens. Using post-hoc interviewer ratings from wave 1 of the National Longitudinal Study of Adolescent Health (Add Health), we examine the degree to which religious teens are perceived more positively than their nonreligious peers. Associations linked to six dimensions of teen religiosity are considered. Select facets of teen religiosity are associated with more positive interviewer ratings, particularly for interpersonal warmth, thereby providing modest support for hypothesized patterns. Findings are interpreted in light of current theories of religious involvement, interpersonal dispositions, and social competencies.
\end{abstract}

Keywords: adolescents; teens; congeniality; social competence; religion; Add Health

\section{Introduction}

Recent research on religion among American teens has demonstrated that religious involvement is a key factor in the lives of youth and provides a host of pro-social effects for adolescents (e.g., Bartkowski 2007; Fletcher and Kumar 2014; French et al. 2013; Hardie et al. 2016; Lytra et al. 2016; Pearce and Denton 2011; Sabatier et al. 2011; Smith and Denton 2005). At the same time, current evidence reveals that religious involvement enhances interpersonal orientations among adults such that religious adherents are generally perceived to be "nice people" (Ellison 1992; Morgan 1983). The current study augments these parallel bodies of scholarship on religion among teens and the linkages between religious involvement and interpersonal orientations by exploring the extent to which adult perceptions of teens vary by adolescent religiosity. In short, this study attempts to determine the degree to which religious teens are perceived as "nice kids".

We seek to address this issue by first discussing the role of religion in the lives of American teens, after which we review the effects of religious involvement on interpersonal congeniality among adults. Based on these bodies of research, we generate a series of hypotheses about the relation between adolescent religious involvement and adult perceptions of religious and nonreligious teens. We then examine post-hoc interviewer ratings of respondents from the National Longitudinal Study of Adolescent Health (Add Health). Add Health interviewer rating data, when coupled with various measures of adolescent respondent religiosity, enable us to explore whether religious interviewees were perceived differently with respect to (1) interpersonal warmth (personality attractiveness), (2) candor, 
and (3) patience and attentiveness. Our investigation ends with a discussion of the findings of this study and an identification of several directions for future research.

\section{Religion among American Teens}

In the last twenty years, a great deal of attention has been paid to the role of religion in socializing young people. About 85 percent of teens claim a denominational affiliation, and the same proportion believe in God (e.g., Pearce and Denton 2011; Smith and Denton 2005; Smith and Faris 2002; see Bartkowski 2007 for a review). Just over half of all teens are Protestant, while one quarter of teens are Catholic. Moreover, about 60 percent of high school seniors report that religion is important in their lives, with about one in every three rating religion as "very important" to them (Smith and Faris 2002). Youth affiliated with more theologically conservative traditions (evangelicals, Latter-day Saints/LDS) are especially inclined to rate their faith as highly important (Smith 2003; Smith and Denton 2005). Nearly one third of all high school seniors attend religious services at least once per week (Smith and Faris 2002). However, teen religiosity varies by sociodemographic factors, such as gender, age, and race, such that girls, younger adolescents, and African American youth tend to exhibit higher levels of religiosity than their peers (Milevsky and Levitt 2004; Milot and Ludden 2009; Smith and Faris 2002; Smith and Denton 2005).

National Study of Youth and Religion (NSYR) data reveal a more detailed portrait of youth religiosity, showing that conservative Protestant and LDS teens attend religious services at extremely high rates when compared with other religiously active youth. More than one in three American teens is actively involved in religious youth group activities (Smith and Denton 2005), and long-term participation in religious youth programs far eclipses teen involvement in extracurricular activities, boys or girls' clubs, and community youth organizations (Smith and Faris 2002). Nearly four in ten NSYR respondents claimed current religious youth group involvement, with conservative Protestant (56 percent) and Latter-day Saint (72 percent) showing greatest involvement. A wealth of evidence reveals that religious communities play a major role in providing adolescents with positive adult role models, pro-social peer associations, and meaningful social skills that insulate religious youth from risks commonly faced by teens; moreover, religious youth tend to be quite civically engaged and highly oriented toward community service (see Bartkowski 2007; Gibson 2008; Regnerus et al. 1998; Smith 2003 for reviews). Building on these contributions, Pearce and Denton (2011) followed adolescents and young adults over the course of three years. They contend that while religion remains important in the lives of most adolescents, their religious development changes over time, in degree and nature simultaneously, as adolescents experience rapid life changes.

Several different explanations have been offered regarding the protective effects that religious involvement confers on teenagers. They can be grouped generally into three categories: (1) moral order, (2) learned competencies, and (3) social and organizational ties (Smith and Denton 2005). Religious involvement provides youth with moral directives (e.g., self-control, virtuous action) that are likely to have a strong influence on teens' life choices (Dowling et al. 2003; Hardy and Carlo 2005). Religion also provides a ground for cultivating particular capacities, such as leadership skills or coping strategies, that might help youth navigate the challenges and vagaries of adolescence while developing character and a positive self-image (Abdel-Khalek 2007, 2011; Ball et al. 2003; Laird et al. 2011; Milevsky and Levitt 2004; Milot and Ludden 2009; Yonker et al. 2012). Finally, youth embedded within religious institutions have a deep reservoir of social capital available to them (intergenerational ties, community linkages) (King and Furrow 2004), and would be more likely to situate them in an interlocking set of relationships composed of various adults that foster network closure (mutual guidance and oversight of youth by a range of adults sharing similar values).

\section{Congeniality Reconsidered: Religion and Teen "Niceness"}

A parallel body of scholarship reveals that religion has a salutary effect on the interpersonal orientations of adults. Religious organizations are a key conduit for social capital, 
civic engagement, and altruistic orientations among adults (e.g., Ammerman 1997; Dury et al. 2015; Ellison and George 1994; Gottlieb and Gillespie 2008; Lewis et al. 2013; Musick et al. 2000; Okun et al. 2007; Park and Smith 2000; Putnam 2000; Regnerus et al. 1998; Wuthnow 1999). Several studies have also shown that religious adults are perceived as more compassionate, friendly, and cooperative than their nonreligious counterparts (Ellison and Sherkat 1990; Ellison 1992; Morgan 1983). In a particularly innovative study, Ellison (1992) demonstrated that interviewers for the National Survey of Black Americans perceived religious respondents to be significantly friendlier and less hostile during the interview encounter than their nonreligious peers. Ellison explored the effects of both private and public forms of religiosity.

Private (or subjective) religiosity, typically defined as frequency of prayer, intensity of religious beliefs, and/or the internalization of religious norms and values (Ellison 1992; Morgan 1983), can be linked to pro-social orientations in a number of ways. First, individuals who have established a personal relationship with a divine other through prayer or devotional readings may develop interpersonal relationships with concrete others in a similar fashion and come to view themselves and their situations by understanding how a divine other would want them to behave (Capps 1982; Ellison 1992; Holm 1987; McCullough and Willoughby 2009; Morgan 1983; Wikström 1987). Morgan (1983), and more recently Robbins et al. (2010), found prayer to be strongly correlated with an intrinsic religious motivation that, in turn, predisposed respondents to more positive behaviors (e.g., friendliness, cooperativeness, agreeableness). Where youth are concerned, this private dimension of religiosity may provide a stabilizing function (meaning, direction, identity) for teens who would otherwise be casting about for an identity during the tumultuous time of adolescence.

Second, religious stories or parables (e.g., the Good Samaritan) may serve as examples that direct religious persons to treat others with empathy and compassion (Ellison 1992; Wuthnow 1999). For example, research on the value orientations of adolescents has revealed a strong positive association between religious salience and self-reported compassionate behavior (Beutel and Marini 1995). Thus, religious involvement can encourage empathy (i.e., taking the role of the other) and self-sacrifice, often through theological imperatives, such as "love thy neighbor". At the same time, a failure to help others may result in religiously inspired feelings of guilt and shame (Ellison 1992; Grasmick et al. 1991), thereby leading teens to engage in more pro-social behaviors.

Public religiosity, which is typically operationalized as denominational affiliation, worship service attendance, and religious youth group involvement, entails integration within networks of coreligionists (Ellison 1992; Morgan 1983; Smith and Denton 2005). Though Ellison (1992), in his earlier study on religion and niceness, found no relation between public dimensions of religiosity and interpersonal congeniality for African American adults, more recent research has found the opposite. Grayman-Simpson and Mattis (2013) discovered that worship service attendance was positively associated with informal community volunteering. There are several reasons to believe that youth who are involved in religious communities would be friendlier and more cooperative than their nonreligious peers. First, public religious participation in worship services and youth groups exposes adherents to messages of kindness through sermons, liturgies, and lessons taught to reinforce benevolent orientations (Ellison 1992; Smith and Denton 2005). Previous evidence has suggested a link between young people's religious participation and benevolent value orientations (e.g., Beutel and Marini 1995; see Bartkowski 2007).

Second, many religious communities share a standard of interpersonal congeniality (e.g., the Golden Rule) and sometimes sanction those who do not conduct themselves in such a manner (Ellison 1992). Regular worship service attendance and youth group participation can provide teens with the opportunity to cultivate and practice social skills ranging from risk aversion to social congeniality (e.g., Bartkowski and Xu 2007; Meier 2003; Regnerus 2007; see Bartkowski 2007 for a review). With such interaction styles demonstrated for youth by both positive adult role models and their pro-social peers, religious institutions may serve as an incubator for the cultivation and transmission of social competence. These effects would likely be most pronounced among youth who 
are heavily invested in public religious expressions (e.g., those who attend frequently and are highly involved in youth activities).

\section{Research Hypotheses}

Given the foregoing review of existing research, we hypothesize that all dimensions of religiosity will be positively associated with perceived pro-social orientations of interpersonal warmth, candor, and patience and attentiveness. Specific hypotheses follow.

Hypothesis 1 (H1). Given the role of religious norms and culture in shaping youth competencies, dispositions, and outcomes, teens affiliated with a denomination will be perceived more positively than their unaffiliated peers.

Hypothesis 2 (H2). Given the importance of religious networks in modeling and transmitting social competencies, teens who regularly attend religious worship services and those who frequently participate in religious youth groups will be perceived more positively than their less involved or uninvolved peers.

Hypothesis 3 (H3). Robust levels of subjective religiosity—namely, scriptural views and religious salience-will be positively associated with more sanguine perceptions of teens because these measures reflect the internalization of religious values and imperatives.

Hypothesis 4 (H4). Finally, teens who pray frequently will be perceived more positively because such an activity is expected to bolster social competencies (e.g., empathy, articulateness, cooperativeness) that would be viewed as desirable.

\section{Data and Methods}

\subsection{Data}

To examine these issues, this study uses data from wave 1 of the National Longitudinal Study of Adolescent Health (Add Health) (see Bearman et al. 1997; Chantala and Tabor 1999; Tourangeau and Shin 1998) analyzed through SPSS, Amos, and Stata. Add Health provides a range of survey data measures designed to examine how social contexts (e.g., peers, families, schools, neighborhoods, and communities) influence the health and risk behaviors of adolescents. Add Health is ideal for the purposes of this study because it provides detailed post-hoc interviewer ratings of interviewees along a number of different dimensions. Add Health also features a series of measures gauging different facets of adolescent religious involvement. Wave 1 of Add Health's in-home data collection sampling and interviewing procedures yielded an initial sample of 20,774 adolescents. In this particular study, a sample of approximately 17,150 adolescents is used due to the combination of missing cases and incomplete answers for the dependent variables under study. Using a multiple imputation method built in Amos, missing cases in students' academic performance (used as a control variable) were imputed to retain as many cases as possible. The cases that were lost in the current analyses are largely due to the missing values in denominational affiliation, gender, and sample weights, which cannot be imputed.

\subsection{Dependent Variables: Interviewer Assessments of Respondent}

At the conclusion of the in-home interview with adolescents, interviewers recorded their perceptions of teen respondents. Each interviewer was asked to describe the respondent, the neighborhood where the interview took place, and the circumstances and surroundings of the interview. Three such interviewer assessments of the adolescents are of interest in this study: (1) interpersonal warmth (personality attractiveness), (2) candor, and (3) patience and attentiveness. These measures of congeniality are consonant with those used in previous research on religion among adults (Ellison 1992). Interpersonal warmth was measured by an item tapping perceptions of the 
attractiveness of the respondent's personality. Respondents were rated on a five-point scale ranging from "very unattractive" (1) to "very attractive" (5). The respondent's candor was rated from "very candid" (1) to "not candid" (4) and then reverse-coded so that a higher number indicated more candor. The interviewer also indicated whether or not the respondent seemed impatient or bored during the interview, and the yes/no responses were coded so that negative replies to these questions indicated patience and attentiveness.

\subsection{Independent Variables: Religiosity of the Respondent}

Consistent with arguments that adolescent religiosity is best understood as a multidimensional construct (Pearce et al. 2017), teen respondent religiosity was measured by a series of items. First, respondents were asked to indicate their denominational affiliation. Based on the Musick et al. (2000) widely utilized coding scheme, religious denominations were categorized as follows: Conservative Protestants (Adventist, Assemblies of God, Baptist, Christian Science, Holiness, Jehovah's Witness, Pentecostal, Presbyterian Church of America), Mainline Protestants (Christian Church-Disciples of Christ, Congregational, Episcopal, Friends/Quaker, Lutheran, Methodist, Presbyterian Church-USA, United Church of Christ, other Protestant, Eastern Orthodox, Unitarian), Black Protestants (AME/AME Zion/CME, National Baptist), Catholic, Jewish, Mormon, Other Religion (Baha'i, Buddhist, Hindu, Islam/Moslem/Muslim, other), and not affiliated. As is common in survey-based studies with limited religion measures, there is no certain means for distinguishing respondents who attend non-denominational Christian Protestant congregations. Our analyses proceed with this limitation in mind.

Next, respondents were asked about the importance of religion to them, with responses ranging from "very important" (1) to "not important at all" (4). Frequency of personal prayer was ascertained with responses ranging from "at least once a day" (1) to "never" (5), reverse-coded. Theological views were measured by determining the extent to which respondents agreed that the sacred scriptures of their religion were the word of God and without mistakes. Responses include "agree" (1), "disagree" (2), and "religion does not have sacred scriptures" (3).

Respondents were asked their frequency of worship service attendance in the past twelve months, with responses ranging from "once a week or more" (1) to "never" (4). They were also asked about their involvement in a religious youth group, with responses ranging from "once a week or more" (1) to "never" (4). For both of these independent variables, scores were reverse-coded so that greater numbers indicate higher levels of attendance and involvement.

\subsection{Control Variables}

As noted above, teen religiosity varies along a number of different dimensions, including gender, age, and race (e.g., Smith and Denton 2005), even as social competence, interaction skills, and perceived congeniality can be affected by a number of non-religious factors (Ellison 1992; Morgan 1983). Consequently, we control for an array of potentially confounding personal characteristics, namely, respondents' age, gender, and academic performance. Due to high correlations between race/ethnicity and denominational affiliation, we do not control for respondents' race/ethnicity. In addition, we control for a series of environmental factors that may influence congeniality, including parental education (parent is college-educated), parental employment (employed versus unemployed), and family structure (intact family versus other family structure). We also consider the potential mediating role of social psychological factors and control for individual self-reported factors, such as the tendency to argue with and be critical of others, as well as the self-esteem of the respondent. Self-esteem is measured via a four-item index. Teen respondents were asked whether or not they agreed or disagreed with the following statements describing themselves: (a) "You have a lot of good qualities", (b) "You have a lot to be proud of", (c) "You like yourself just the way you are", and (d) "You feel like you are doing everything just about right" $(\alpha=0.789)$. Moreover, previous research on perceptions of niceness and religion among American teenagers include controls for these factors, so we follow the lead of previous 
scholarship in introducing these covariates (Abdel-Khalek 2007; Beutel and Marini 1995; Ellison 1992; Kugler and Hansson 1988; Wallace et al. 2003).

\subsection{Analytical Procedures}

To examine the associations between teen religiosity and interviewer assessments of respondent interpersonal warmth and candor, ordered logistic regression was employed. Logistic regression was used to analyze the associations between teen religiosity and interviewer perceptions of the respondents' patience and attentiveness. Unless stated otherwise, the complex sample design in Stata was utilized to weight and analyze the data.

\section{Results}

In Table 1, we display the estimated proportions and means based on the full sample before listwise deletion for all variables used in the study.

Table 1. The Sample Proportions and Means before Listwise Deletion.

\begin{tabular}{|c|c|c|c|c|}
\hline & $\begin{array}{l}\text { Estimated } \\
\text { Proportion }\end{array}$ & $\mathbf{n}$ & $\begin{array}{l}\text { Estimated } \\
\text { Means }\end{array}$ & $\begin{array}{c}\text { Estimated } \\
\text { SD }\end{array}$ \\
\hline Interpersonal Warmth & - & - & 3.59 & 0.02 \\
\hline Candor & - & - & 3.34 & 0.02 \\
\hline \multicolumn{5}{|l|}{ Patience and Attentiveness } \\
\hline Yes & 0.87 & 2398 & - & - \\
\hline No & 0.13 & 16,503 & - & - \\
\hline Age & & & 15.89 & 0.12 \\
\hline \multicolumn{5}{|l|}{ Gender } \\
\hline Male & 0.51 & 9630 & - & - \\
\hline Female & 0.49 & 9292 & - & - \\
\hline Self Esteem & - & - & 1.88 & 0.01 \\
\hline Argument & - & - & 3.79 & 0.02 \\
\hline Critical & - & - & 3.24 & 0.02 \\
\hline Academic Performance & - & - & 2.80 & 0.02 \\
\hline \multicolumn{5}{|l|}{ Family Structure } \\
\hline Intact Family & 0.38 & 7126 & - & - \\
\hline Other Family Structure & 0.62 & 11,798 & - & - \\
\hline \multicolumn{5}{|l|}{ Parent's Education } \\
\hline College Educated & 0.35 & 6533 & - & - \\
\hline Below College & 0.65 & 12,391 & - & - \\
\hline \multicolumn{5}{|l|}{ Parent's Employment } \\
\hline Employed & 0.63 & 11,937 & - & - \\
\hline Unemployed & 0.37 & 6987 & - & - \\
\hline \multicolumn{5}{|l|}{ Denominational Affiliation } \\
\hline Not Affiliated & 0.13 & 2380 & - & - \\
\hline Conservative Protestant & 0.19 & 3601 & - & - \\
\hline Mainline Protestant & 0.24 & 4413 & - & - \\
\hline Black Protestant & 0.12 & 2194 & - & - \\
\hline Catholic & 0.25 & 4595 & - & - \\
\hline Jewish & 0.01 & 146 & - & - \\
\hline Mormon & 0.01 & 186 & - & - \\
\hline Other Religion & 0.06 & 1039 & - & - \\
\hline Church Attendance & & & 2.68 & 0.03 \\
\hline Religious Youth Group & & & 2.02 & 0.03 \\
\hline \multicolumn{5}{|l|}{ Sacred Scripture } \\
\hline Yes & 0.65 & 11,863 & - & - \\
\hline No & 0.35 & 6415 & - & - \\
\hline Religion Important & - & - & 2.99 & 0.03 \\
\hline Pray & - & - & 3.51 & 0.04 \\
\hline
\end{tabular}


In Tables 2-4, Model 1 estimates the associations between the control variables and interviewer perceptions of teen respondents. Models 2-7 estimate the associations evident between key independent variables-denomination, worship service attendance, youth group participation, scriptural views, religious salience, and prayer, respectively-and each of the dependent variables (interpersonal warmth in Table 2, candor in Table 3, and patience-attentiveness in Table 4). Model 8 in each table features the results of the full model for all of the religious variables and control variables.

A few caveats are warranted before turning to the findings. First, the size of the subsample varies slightly across the dependent variables under study due to the exclusion of missing cases and incomplete answers for our multivariate statistical analyses. Second, respondent race was dropped from the regression analyses because it was collinear with Black Protestant, a key variable of interest. Third, while Model 8 features the associations of all religious factors and covariates with our dependent variables, we give greater heed to the results in Models 2-7. Including all religious factors in a single model (Model 8) of Tables 2-4 introduces collinearity that, while slight, is enough to yield discrepant findings for a few factors. Thus, while Model 8 is presented to conform to scientific convention, the results in the preceding models are the most valid indicators of religious associations. Finally, in reporting results, we sometimes use the word "effects" for stylistic convenience but are aware that cross-sectional data detect associations in which directionality must be presumed. Our arguments about religious factors producing specific effects follows from previous research. We now turn to our findings.

Table 2 features the results of ordered logistic regression models estimating the net effects of the six religion variables on interviewer ratings related to the perceived interpersonal warmth (personality attractiveness) of the respondents. Hypothesis 1 is generally supported in Model 2 of Table 2. Adolescent affiliation with five of seven denominations produces significantly more salutary perceptions of teen interpersonal warmth when compared with interviewer evaluations of unaffiliated teens. Borderline significance is observed for Catholic teens. Hypothesis 2 predicted that religious network integration (worship service attendance and youth group involvement) would be related to interpersonal warmth, but is not supported (Models 3 and 4, Table 2). Hypothesis 3, which anticipated the relation between subjective forms of religiosity, that is, scriptural views (Model 5) and religious salience (Model 6), is partially supported because only salience is positively related to sanguine perceptions of teens' interpersonal warmth. Additionally, as expected in Hypothesis 4, frequency of prayer among adolescents (Model 7) is significantly and positively associated with interpersonal warmth. The only consistent effects observed in the full model are those associated with religious salience and frequency of prayer.

Table 3 displays ordered logistic regression models estimating the net effects of the six religion variables on interviewer ratings related to the perceived candor of teen respondents. Ratings of candor for Jewish teens achieve positive significance in Model 2. This finding lends some (albeit weak) support to Hypothesis 1 about general denominational effects. Teens affiliated with a Black Protestant denomination also achieve significance in Model 2, but in the opposite direction of what was expected. No other hypotheses are confirmed in Table 3. Hypotheses 2 and 3 reveal borderline significance but in the opposite direction, with youth group participation and subjective forms of religiosity (scriptural views) serving as negative predictors of perceptions of teen candor. 
Table 2. Ordered Logistic Regression to Predict Interpersonal Warmth. ${ }^{a}$

\begin{tabular}{|c|c|c|c|c|c|c|c|c|c|c|c|c|c|c|c|c|}
\hline & Model 1 & & Model 2 & & Model 3 & & Model 4 & & Model 5 & & Model 6 & & Model 7 & & Model 8 & \\
\hline Age & 0.057 & $* * *$ & 0.060 & $* * *$ & 0.059 & $* * *$ & 0.059 & $* * *$ & 0.057 & $* * *$ & 0.059 & $* * *$ & 0.059 & $* * *$ & 0.060 & $* * *$ \\
\hline Gender & 0.400 & $* * *$ & 0.405 & $* * *$ & 0.395 & $* * *$ & 0.396 & $* * *$ & 0.400 & $* * *$ & 0.388 & $* * *$ & 0.382 & $* * *$ & 0.383 & $* * *$ \\
\hline Self Esteem & -0.313 & $* * *$ & -0.326 & $* * *$ & -0.308 & $* * *$ & -0.309 & $* * *$ & -0.312 & $* * *$ & -0.297 & $* * *$ & -0.299 & $* * *$ & -0.317 & $* * *$ \\
\hline Argument & 0.011 & & 0.009 & & 0.012 & & 0.011 & & 0.011 & & 0.012 & & 0.013 & & 0.010 & \\
\hline Critical & -0.017 & & -0.014 & & -0.017 & & -0.016 & & -0.016 & & -0.015 & & -0.016 & & -0.015 & \\
\hline Academic Performance & 0.383 & $* * *$ & 0.366 & $* * *$ & 0.377 & $* * *$ & 0.380 & $* * *$ & 0.384 & $* * *$ & 0.377 & $* * *$ & 0.372 & $* * *$ & 0.353 & $* * *$ \\
\hline Intact Family & -0.031 & & -0.075 & & -0.038 & & -0.033 & & -0.031 & & -0.038 & & -0.036 & & -0.071 & \\
\hline Parent's Education & 0.202 & $* * *$ & 0.200 & $* * *$ & 0.199 & $* * *$ & 0.200 & $* * *$ & 0.202 & $* * *$ & 0.204 & $* * *$ & 0.197 & $* * *$ & 0.188 & $* * *$ \\
\hline Parent is Employed & 0.106 & $*$ & 0.116 & $* *$ & 0.106 & * & 0.106 & $*$ & 0.106 & $*$ & 0.105 & $*$ & 0.104 & * & 0.113 & * \\
\hline Conservative Protestant & & & 0.294 & $* * *$ & & & & & & & & & & & 0.098 & \\
\hline Mainline Protestant & & & 0.252 & $* *$ & & & & & & & & & & & 0.074 & \\
\hline Black Protestant & & & -0.051 & & & & & & & & & & & & -0.269 & * \\
\hline Catholic & & & 0.145 & + & & & & & & & & & & & -0.046 & \\
\hline Jewish & & & 0.442 & * & & & & & & & & & & & 0.274 & \\
\hline Mormon & & & 0.413 & * & & & & & & & & & & & 0.203 & \\
\hline Other Religion & & & 0.237 & $*$ & & & & & & & & & & & 0.043 & \\
\hline Church Attendance & & & & & 0.039 & + & & & & & & & & & -0.013 & \\
\hline Religious Youth Group & & & & & & & 0.028 & & & & & & & & -0.004 & \\
\hline Sacred Scripture & & & & & & & & & 0.009 & & & & & & -0.160 & $* *$ \\
\hline Religion Important & & & & & & & & & & & 0.076 & $* *$ & & & 0.080 & $*$ \\
\hline Pray & & & & & & & & & & & & & 0.058 & $* * *$ & 0.055 & * \\
\hline $\mathrm{n}$ & 17,159 & & 17,159 & & 17,159 & & 17,159 & & 17,159 & & 17,159 & & 17,159 & & 17,159 & \\
\hline
\end{tabular}


Table 3. Ordered Logistic Regression to Predict Candor. ${ }^{\mathrm{a}}$

\begin{tabular}{|c|c|c|c|c|c|c|c|c|c|c|c|c|c|c|c|c|}
\hline & Model 1 & & Model 2 & & Model 3 & & Model 4 & & Model 5 & & Model 6 & & Model 7 & & Model 8 & \\
\hline Age & 0.052 & * & 0.053 & * & 0.050 & * & 0.049 & * & 0.050 & * & 0.051 & * & 0.052 & * & 0.050 & * \\
\hline Gender & 0.073 & & 0.090 & & 0.077 & & 0.078 & & 0.074 & & 0.076 & & 0.075 & & 0.086 & \\
\hline Self Esteem & -0.125 & $* * *$ & -0.155 & $* * *$ & -0.129 & $* *$ & -0.130 & $* * *$ & -0.134 & $* *$ & -0.129 & $* *$ & -0.127 & $* *$ & -0.157 & $* * *$ \\
\hline Argument & 0.059 & * & 0.063 & $* *$ & 0.058 & * & 0.059 & $*$ & 0.059 & * & 0.059 & $*$ & 0.059 & $*$ & 0.062 & $* *$ \\
\hline Critical & 0.014 & & 0.014 & & 0.014 & & 0.013 & & 0.012 & & 0.014 & & 0.014 & & 0.014 & \\
\hline Academic Performance & 0.168 & $* * *$ & 0.141 & $* * *$ & 0.173 & $* * *$ & 0.173 & $* * *$ & 0.168 & $* * *$ & 0.169 & $* * *$ & 0.169 & $* * *$ & 0.141 & $* * *$ \\
\hline Intact Family & 0.087 & + & 0.030 & & 0.093 & $*$ & 0.090 & + & 0.094 & $*$ & 0.089 & + & 0.088 & + & 0.039 & \\
\hline Parent's Education & 0.115 & $t$ & 0.104 & & 0.118 & $t$ & 0.117 & t & 0.110 & $t$ & 0.115 & $t$ & 0.116 & $t$ & 0.102 & \\
\hline Parent is Employed & 0.139 & $* *$ & 0.149 & $* *$ & 0.139 & $* *$ & 0.139 & $* * *$ & 0.137 & $* *$ & 0.139 & $* * *$ & 0.139 & $* *$ & 0.147 & $* *$ \\
\hline Conservative Protestant & & & 0.038 & & & & & & & & & & & & 0.091 & \\
\hline Mainline Protestant & & & 0.042 & & & & & & & & & & & & 0.088 & \\
\hline Black Protestant & & & -0.381 & $* * *$ & & & & & & & & & & & -0.327 & $* *$ \\
\hline Catholic & & & 0.139 & & & & & & & & & & & & 0.174 & \\
\hline Jewish & & & 0.725 & $* * *$ & & & & & & & & & & & 0.735 & $* * *$ \\
\hline Mormon & & & 0.126 & & & & & & & & & & & & 0.187 & \\
\hline Other Religion & & & 0.169 & & & & & & & & & & & & 0.204 & \\
\hline Church Attendance & & & & & -0.032 & & & & & & & & & & -0.028 & \\
\hline Religious Youth Group & & & & & & & -0.037 & + & & & & & & & -0.012 & \\
\hline Sacred Scripture & & & & & & & & & -0.111 & + & & & & & -0.120 & + \\
\hline Religion Important & & & & & & & & & & & -0.018 & & & & 0.032 & \\
\hline Pray & & & & & & & & & & & & & -0.007 & & 0.015 & \\
\hline $\mathrm{n}$ & 17,152 & & 17,152 & & 17,152 & & 17,152 & & 17,152 & & 17,152 & & 17,152 & & 17,152 & \\
\hline
\end{tabular}

${ }^{a}$ Design effects are corrected with robust standard errors and weights. $+p<0.10$; $^{*} p<0.05$; ${ }^{* *} p<0.01$; ${ }^{* * *} p<0.001$. 
Table 4. Logistic Regression to Predict Patience and Attentiveness. ${ }^{\text {a }}$

\begin{tabular}{|c|c|c|c|c|c|c|c|c|c|c|c|c|c|c|c|c|}
\hline & Model 1 & & Model 2 & & Model 3 & & Model 4 & & Model 5 & & Model 6 & & Model 7 & & Model 8 & \\
\hline Age & 0.036 & & 0.036 & & 0.039 & & 0.038 & & 0.039 & & 0.038 & & 0.039 & & 0.040 & \\
\hline Gender & 0.517 & $* * *$ & 0.520 & $* * *$ & 0.508 & $* * *$ & 0.513 & $* * *$ & 0.515 & $* * *$ & 0.508 & $* * *$ & 0.496 & $* * *$ & 0.505 & $* * *$ \\
\hline Self Esteem & -0.167 & $*$ & -0.170 & $*$ & -0.160 & * & -0.163 & $*$ & -0.157 & $*$ & -0.155 & $*$ & -0.153 & + & -0.161 & $*$ \\
\hline Argument & -0.034 & & -0.032 & & -0.032 & & -0.034 & & -0.034 & & -0.033 & & -0.032 & & -0.029 & \\
\hline Critical & -0.053 & & -0.053 & & -0.053 & & -0.053 & & -0.051 & & -0.052 & & -0.052 & & -0.051 & \\
\hline Academic Performance & 0.295 & $* * *$ & 0.282 & $* * *$ & 0.282 & $* * *$ & 0.290 & $* * *$ & 0.293 & $* * *$ & 0.288 & $* * *$ & 0.281 & $* * *$ & 0.268 & $* * *$ \\
\hline Intact Family & -0.078 & & -0.091 & & -0.090 & & -0.081 & & -0.087 & & -0.084 & & -0.083 & & -0.100 & \\
\hline Parent's Education & 0.151 & $t$ & 0.151 & $t$ & 0.145 & $t$ & 0.149 & $t$ & 0.157 & $\dagger$ & 0.151 & $t$ & 0.145 & $t$ & 0.142 & $t$ \\
\hline Parent is Employed & 0.185 & * & 0.188 & & 0.184 & * & 0.185 & * & 0.187 & * & 0.184 & * & 0.182 & * & 0.189 & $*$ \\
\hline Conservative Protestant & & & 0.117 & & & & & & & & & & & & -0.131 & \\
\hline Mainline Protestant & & & 0.100 & & & & & & & & & & & & -0.125 & \\
\hline Black Protestant & & & 0.059 & & & & & & & & & & & & -0.212 & \\
\hline Catholic & & & 0.173 & & & & & & & & & & & & -0.054 & \\
\hline Jewish & & & 0.453 & & & & & & & & & & & & 0.314 & \\
\hline Mormon & & & 0.042 & & & & & & & & & & & & -0.230 & \\
\hline Other Religion & & & 0.560 & $* *$ & & & & & & & & & & & 0.341 & \\
\hline Church Attendance & & & & & 0.065 & $t$ & & & & & & & & & 0.040 & \\
\hline Religious Youth Group & & & & & & & 0.032 & & & & & & & & -0.003 & \\
\hline Sacred Scripture & & & & & & & & & 0.137 & + & & & & & 0.099 & \\
\hline Religion Important & & & & & & & & & & & 0.056 & & & & -0.031 & \\
\hline Pray & & & & & & & & & & & & & 0.059 & $* *$ & 0.059 & \\
\hline $\mathrm{n}$ & 17,161 & & 17,161 & & 17,161 & & 17,161 & & 17,161 & & 17,161 & & 17,161 & & 17,161 & \\
\hline
\end{tabular}

${ }^{a}$ Design effects are corrected with robust standard errors and weights. $+p<0.10$; $^{*} p<0.05$; ${ }^{* *} p<0.01$; ${ }^{* * *} p<0.001$. 
Turning next to perceptions of teens' patience and attentiveness in Table 4, adolescents affiliated with other (generally, non-Christian) religious traditions are perceived more favorably than their nonreligious peers (Model 2). This finding lends weak support to Hypothesis 1 about general denominational effects. Neither worship service attendance nor youth group participation is significantly associated with patience and attentiveness (Model 3), thereby disconfirming Hypothesis 2 with respect to this dependent variable. Hypothesis 3 is not supported because neither beliefs about sacred scripture nor religious salience has a significant effect on perceived patience and attentiveness. Hypothesis 4 is fully supported inasmuch as prayer is significantly predictive of interviewers' perceptions of patience and attentiveness in teen respondents. No significant associations, however, survive in the full model.

\section{Discussion}

This study has examined the associations between various dimensions of religiosity and three pro-social orientations among adolescents: (1) interpersonal warmth (personality attractiveness), (2) candor, and (3) patience and attentiveness. Based on our review of the literatures on religious teens and faith-inspired congeniality, we anticipated that the normative infrastructure of religious organizations (denominational affiliation), the pro-social religious networks of congregational involvement (worship service attendance, youth group participation), the internalized convictions of a religious worldview (scriptural views, religious salience), and the practice of private devotion (prayer) would produce salutary effects across all of these dimensions of "niceness". We examined post-hoc interviewer ratings of teen respondents from wave 1 of Add Health to determine if such hypotheses were empirically supported, paying closest attention to the effects of adolescent religiosity on interviewer ratings related to these three dimensions of niceness.

We found that adolescent religious characteristics exert mixed effects on adult perceptions of teens as "nice kids". The lack of consistently significant associations across dependent variable indicators underscores the value of examining each specific component of congeniality, as we have done here, rather than combining them into a single index variable. We would suggest continued adherence to an indicator-specific approach in replication efforts using other data sources. The most noteworthy religious effects were observed with respect to interpersonal warmth, where statistically significant findings surfaced for three of six measures of religion (namely, affiliation with most denominations, religious salience, and frequency of prayer). (Worship service attendance achieved borderline significance for the interpersonal warmth dependent variable, but still fell short of the conventional threshold of statistical significance.) The effects of teen religiosity were less robust for perceived candor. On this front, more circumscribed and, in fact, mixed denominational effects were observed (positive for Jewish teens, negative for Black Protestants). The effects of religion were somewhat more robust for evaluations of patience and attentiveness, where select denominational effects (affiliation with other, generally non-Christian, denominations) were observed in combination with the positive effects of frequent prayer.

Prayer was significantly and positively associated with salutary perceptions of interpersonal warmth and patience-attentiveness. Why would frequent teen prayer serve as a more consistent predictor than other forms of religiosity? The short answer to this question is that when practiced as a regular discipline, prayer may cultivate social skills and dispositions (articulacy, empathy, attentiveness) that are valuable for navigating social encounters. Of course, the influences of other religious factors are considerably less consistent. While inconsistent findings associated with various religious factors could be seen as vexing, they actually teach a valuable lesson, namely, gross religiosity does not count for much where youth congeniality is concerned. Rather, specific types of religious involvement and devotion (e.g., denominational affiliation, prayer) inculcate particular dispositions toward congeniality.

The findings observed here, of course, beg for additional research designed to overcome some of the limitations inherent in this investigation. For example, the first wave of Add Health data 
does not permit us to control for interviewer characteristics. Follow-up research on religion and adult perceptions of young people should be conducted with datasets that permit controls for such an important factor, given that interviewers' perceptions may be shaped by their own social characteristics and perhaps their own religious involvement. Moreover, given our focus on U.S. adolescents, one promising line of future research could seek to determine if the results observed here are replicable in other national contexts. As research on global religion continues to gain traction (see, e.g., the Global Religion Research Initiative, https:/ / grri.nd.edu/, accessed on 20 October 2018), a comparative vantage point on congeniality among youth in various international contexts may ultimately be possible.

In addition, future research could explore the effects of secular civic participation versus religious participation in relation to perceptions of niceness. It is possible that it is not religion per se that produces pro-social perceptions of teens, but rather general social engagement (e.g., involvement in school clubs, secular youth groups, and sports teams). Given research that has revealed the positive effects of such activities in the lives of teens (Bartkowski and Xu 2007), comparisons of religious effects versus secular effects would make for an intriguing extension of our study. This line of research is especially needed because there is some evidence from repeated cross-sectional data that American teens have become less religious over time (Twenge et al. 2015). Panel data also indicate that key life transitions may make religion less attractive to young people (Hardie et al. 2016) and that young people may proceed along various developmental pathways with respect to religion as they transition into adulthood (Lee et al. 2017). Quite notably, even some conservative traditions are adapting to address young people's changing religious preferences (Riess 2019).

We would also encourage the use of longitudinal panel data to explore patterns related to religion and youth congeniality. We have discussed the positive "effects" of religious factors in this investigation. However, we are well aware that correlations do not prove causation. In fact, it is possible that "nice kids" are more welcome in social groups, including religious communities. Therefore, the causal order may be the reverse of what we, following previous research, have presumed. Excellent sources of panel data exist on youth and religion, and such data have been used to examine wide-ranging questions about the contours and antecedents of youth religious development over time (e.g., Denton and Culver 2015; Lee et al. 2017). Such research would be significantly augmented by an exploration of changes in social competence and congeniality across the teen and young adult developmental spectrum. Of course, interviewer-based ratings might not be able to be used for such longitudinal investigations because raters would undoubtedly change from one survey wave to the next, thereby raising questions about comparability. Still, survey items tapping communicative competence, number of friends (religious and non-religious), the subjective valuation of congenial dispositions, and related factors might be explored as proxies for congeniality.

Finally, survey interviews are not a natural conversational setting. Consequently, it is difficult to tell from this study if the particular competencies religious teens exhibited in completing a structured survey are, in fact, transposable to more normal, natural social encounters. Observational research and vignette-based interviews could be used to determine if the congeniality exhibited here is manifested in other social venues. Such intriguing avenues of research, while beyond the scope of this investigation, are definitely worthy of attention. Until such lines of research are pursued, however, this study has revealed that select religious factors have an effect on adult perceptions of teen congeniality.

Author Contributions: K.M.F., X.X., and M.L.L. conducted the data analyses and contributed to the writing and interpretation of the results. J.P.B. completed the majority of the writing and provided primary interpretations.

Funding: This research received no external funding.

Acknowledgments: The authors are grateful for comments offered at public presentations of this paper and for the astute observations shared by anonymous reviewers.

Conflicts of Interest: The authors declare no conflict of interest. 


\section{References}

Abdel-Khalek, Ahmed M. 2007. Religiosity, happiness, health, and psychopathology in a probability sample of Muslim adolescents. Mental Health, Religion \& Culture 10: 571-83.

Abdel-Khalek, Ahmed M. 2011. Religiosity, subjective well-being, self-esteem, and anxiety among Kuwaiti Muslim adolescents. Mental Health, Religion E Culture 14: 129-40.

Ammerman, Nancy Tatom. 1997. Congregation and Community. New Brunswick: Rutgers University Press.

Ball, Joanna, Lisa Armistead, and Barbara-Jeanne Austin. 2003. The relationship between religiosity and adjustment among African American, female, urban adolescents. Journal of Adolescence 26: 431-46. [CrossRef]

Bartkowski, John P. 2007. Religious socialization among American youth: How faith shapes parents, children, and adolescents. In The Sage Handbook of the Sociology of Religion. Edited by James A. Beckford and N.J. Demerath III. Thousand Oaks: Sage, pp. 511-25.

Bartkowski, John P., and Xiaohe Xu. 2007. Religion, social capital, and teen drug use: A preliminary investigation. American Journal of Preventive Medicine 32: S182-94. [CrossRef] [PubMed]

Bearman, Peter S., Jo Jones, and J. Richard Udry. 1997. Research Design. Available online: http:/ /www.cpc.unc. edu/projects/addhealth/design (accessed on 7 July 2018).

Beutel, Ann M., and Margaret Mooney Marini. 1995. Gender and values. American Sociological Review 60: 436-48. [CrossRef]

Capps, Donald. 1982. Sunden's role-taking theory: The case of John Henry Newman and his mentors. Journal for the Scientific Study of Religion 21: 58-70. [CrossRef]

Chantala, Kim, and Joyce Tabor. 1999. National Longitudinal Study of Adolescent Health: Strategies to Perform a Design-Based Analysis Using the Add Health Data. Chapel Hill: Carolina Population Center, University of North Carolina.

Denton, Melinda Lundquist, and Julian Culver. 2015. Family disruption and racial variation in adolescent and emerging adult religiosity. Sociology of Religion 76: 222-39. [CrossRef]

Dowling, Elizabeth M., Steinunn Gestsdottir, Pamela M. Anderson, Alexander von Eye, and Richard M. Lerner. 2003. Spirituality, religiosity, and thriving among adolescents: Identification and confirmation of factor structures. Applied Developmental Science 7: 253-60. [CrossRef]

Dury, Sarah, Liesbeth De Donder, Nico De Witte, Tine Buffel, Wolfgang Jacquet, and Dominique Verté. 2015. To volunteer or not: The influence of individual characteristics, resources, and social factors on the likelihood of volunteering by older adults. Nonprofit and Voluntary Sector Quarterly 44: 1107-28. [CrossRef]

Ellison, Christopher G. 1992. Are religious people nice people? Evidence from the National Survey of Black-Americans. Social Forces 71: 411-30. [CrossRef]

Ellison, Christopher G., and Linda K. George. 1994. Religious involvement, social ties, and social support in a southeastern community: A study of a theoretical model linking institutional church participation and social network relationships. Journal for the Scientific Study of Religion 33: 46-61. [CrossRef]

Ellison, Christopher G., and Darren E. Sherkat. 1990. Patterns of religious mobility among Black Americans. Sociological Quarterly 31: 551-68. [CrossRef]

Fletcher, Jason, and Sanjeev Kumar. 2014. Religion and risky behaviors among U.S. adolescents and adults. Journal of Economic Behavior and Organization 104: 123-40. [CrossRef]

French, Doran C., Nancy Eisenberg, Julie Sallquist, Urip Purwono, Ting Lu, and Sharon Christ. 2013. Parent-adolescent relationships, religiosity, and the social adjustment of Indonesian Muslim adolescents. Journal of Family Psychology 27: 421-30. [CrossRef] [PubMed]

Gibson, Troy. 2008. Religion and civic engagement among America's youth. Social Science Journal 45: 504-14. [CrossRef]

Gottlieb, Ben H., and Alayna A. Gillespie. 2008. Volunteerism, health, and civic engagement among older adults. Canadian Journal on Aging-Revue Canadienne Du Vieillissement 27: 399-406. [CrossRef] [PubMed]

Grasmick, Harold G., Robert J. Bursik, and John K. Cochran. 1991. Render unto Caesar what is Caesar's: Religiosity and taxpayers' inclinations to cheat. Sociological Quarterly 32: 251-66. [CrossRef]

Grayman-Simpson, Nyasha, and Jacqueline S Mattis. 2013. "If it wasn't for the church ... :" Organizational religiosity and informal community helping among African American adults. Journal of African American Studies 17: 243-52. [CrossRef] 
Hardie, Jessica Halliday, Lisa D. Pearce, and Melinda Lundquist Denton. 2016. The dynamics and correlates of religious service attendance in adolescence. Youth $\mathcal{E}$ Society 48: 151-75.

Hardy, Sam A., and Gustavo Carlo. 2005. Religiosity and prosocial behaviours in adolescence: The mediating role of prosocial values. Journal of Moral Education 34: 231-49. [CrossRef]

Holm, Nils G. 1987. Sunden's role theory and glossolalia. Journal for the Scientific Study of Religion 26: $383-89$. [CrossRef]

King, Pamela Ebstyne, and James L. Furrow. 2004. Religion as a resource for positive youth development: Religion, social capital, and moral outcomes. Developmental Psychology 40: 703-13. [CrossRef] [PubMed]

Kugler, Karen E., and Robert O. Hansson. 1988. Relational competence and social support among parents at risk of child abuse. Family Relations 37: 328-32. [CrossRef]

Laird, Robert D., Loren D. Marks, and Matthew D. Marrero. 2011. Religiosity, self-control, and antisocial behavior: Religiosity as a promotive and protective factor. Journal of Applied Developmental Psychology 32: 78-85. [CrossRef]

Lee, Bo Hyeong Jane, Lisa D. Pearce, and Kristen M. Schorpp. 2017. Religious pathways from adolescence to adulthood. Journal for the Scientific Study of Religion 56: 678-89. [CrossRef] [PubMed]

Lewis, Valerie A., Carol Ann MacGregor, and Robert D. Putnam. 2013. Religion, networks, and neighborliness: The impact of religious social networks on civic engagement. Social Science Research 42: 331-46. [CrossRef] [PubMed]

Lytra, Vally, Dinah Volk, and Eve Gregory, eds. 2016. Navigating Languages, Literacies and Identities: Religion in Young Lives. New York: Routledge.

McCullough, Michael E., and Brian L. B. Willoughby. 2009. Religion, self-regulation, and self-control: Associations, explanations, and implications. Psychological Bulletin 135: 69. [CrossRef] [PubMed]

Meier, Ann M. 2003. Adolescents' transition to first intercourse, religiosity, and attitudes about sex. Social Forces 81: 1031-52. [CrossRef]

Milevsky, Avidan, and Mary J. Levitt. 2004. Intrinsic and extrinsic religiosity in preadolescence and adolescence: Effect on psychological adjustment. Mental Health, Religion \& Culture 7: 307-21.

Milot, Alyssa S., and Alison Bryant Ludden. 2009. The effects of religion and gender on well-being, substance use, and academic engagement among rural adolescents. Youth $\mathcal{E}$ Society 40: 403-25.

Morgan, S. Philip. 1983. A research note on religion and morality: Are religious people nice people? Social Forces 61: 683-92. [CrossRef]

Musick, Marc A., John Wilson, and William B. Bynum Jr. 2000. Race and formal volunteering: The differential effects of class and religion. Social Forces 78: 1539-70. [CrossRef]

Okun, Morris A., John Pugliese, and Karen S. Rook. 2007. Unpacking the relation between extraversion and volunteering in later life: The role of social capital. Personality and Individual Differences 42: 1467-77. [CrossRef] [PubMed]

Park, Jerry Z., and Christian Smith. 2000. “To whom much has been given...": Religious capital and community voluntarism among churchgoing Protestants. Journal for the Scientific Study of Religion 39: 272-86. [CrossRef]

Pearce, Lisa, and Melinda Lundquist Denton. 2011. A Faith of Their Own: Stability and Change in the Religiosity of America's Adolescents. New York: Oxford University Press.

Pearce, Lisa D., George M. Hayward, and Jessica A. Pearlman. 2017. Measuring five dimensions of religiosity across adolescence. Review of Religious Research 59: 367-93. [CrossRef] [PubMed]

Putnam, Robert D. 2000. Bowling Alone: The Collapse and Revival of American Community. New York: Simon \& Schuster.

Regnerus, Mark D. 2007. Forbidden Fruit: Sex and Religion in the Lives of American Teens. New York: Oxford University Press.

Regnerus, Mark D., Christian Smith, and David Sikkink. 1998. Who gives to the poor? The influence of religious tradition and political location on the personal generosity of Americans toward the poor. Journal for the Scientific Study of Religion 37: 481-93. [CrossRef]

Riess, Jana. 2019. The Next Mormons: How Millennials Are Changing the LDS Church. New York: Oxford University Press.

Robbins, Mandy, Leslie Francis, David McIlroy, Rachel Clarke, and Lowri Pritchard. 2010. Three religious orientations and five personality factors: An exploratory study among adults in England. Mental Health, Religion $\mathcal{E}$ Culture 13: 771-75. 
Sabatier, Colette, Boris Mayer, Mihaela Friedlmeier, Katarzyna Lubiewska, and Gisela Trommsdorff. 2011. Religiosity, family orientation, and life satisfaction of adolescents in four countries. Journal of Cross-Cultural Psychology 42: 1375-93. [CrossRef]

Smith, Christian. 2003. Theorizing religious effects among American adolescents. Journal for the Scientific Study of Religion 42: 17-30. [CrossRef]

Smith, Christian, and Melina Lundquist Denton. 2005. Soul Searching: The Religious and Spiritual Lives of American Teenagers. New York: Oxford University Press.

Smith, Christian, and Robert Faris. 2002. Religion and American Adolescent Delinquency, Risk Behaviors and Constructive Social Activities. A Research Report of the National Study of Youth and Religion. Chapel Hill: National Study of Youth and Religion.

Steensland, Brian, Lynn D. Robinson, W. Bradford Wilcox, Jerry Z. Park, Mark D. Regnerus, and Robert D. Woodberry. 2000. The measure of American religion: Toward improving the state of the art. Social Forces 79: 291-318. [CrossRef]

Tourangeau, Roger, and H. Shin. 1998. National Longitudinal Study of Adolescent Health: Grand Sample Weight. Chapel Hill: Carolina Population Center, University of North Carolina.

Twenge, Jean M., Julie J. Exline, Joshua B. Grubbs, Ramya Sastry, and W. Keith Campbell. 2015. Generational and time period differences in American adolescents' religious orientation, 1966-2014. PLoS ONE 10: e0121454. [CrossRef] [PubMed]

Wallace, John M., Jr., Tyrone A. Forman, Cleopatra H. Caldwell, and Deborah S. Willis. 2003. Religion and U.S. secondary school students: Current patterns, recent trends, and sociodemographic correlates. Youth E Society 35: 98-125.

Wikström, Owe. 1987. Attribution, roles and religion: A theoretical analysis of Sunden's role theory of religion and the attributional approach to religious experience. Journal for the Scientific Study of Religion 26: 390-400. [CrossRef]

Wuthnow, Robert. 1999. Mobilizing civic engagement: The changing impact of religious involvement. In Civic Engagement in American Democracy. Edited by Theda Skocpol and Morris P. Fiorina. Washington: Brookings Institute Press, pp. 331-63.

Yonker, Julie E., Chelsea A. Schnabelrauch, and Laura G. DeHaan. 2012. The relationship between spirituality and religiosity on psychological outcomes in adolescents and emerging adults: A meta-analytic review. Journal of Adolescence 35: 299-314. [CrossRef] [PubMed]

(c) 2018 by the authors. Licensee MDPI, Basel, Switzerland. This article is an open access article distributed under the terms and conditions of the Creative Commons Attribution (CC BY) license (http:/ / creativecommons.org/licenses/by/4.0/). 